\title{
BOX 4 Seamount Catalog: Seamount Morphology, Maps, and Data Files
}

By Anthony A.P. Koppers, Hubert Staudigel, and Rupert Minnett

Seamount research, more often than not, is carried out by highly specialized science teams with narrowly focused science objectives. As a result, different seamount science disciplines often do not collaborate or are not even aware of each other. However, it is obvious that interdisciplinary collaboration is the most successful approach to help understand the integrated chemical, physical, and biological systems at seamounts. The Seamount Biogeoscience Network (SBN) was founded to promote the necessary cooperation through workshops, publications, and the development of a database that allows all seamount sciences to share data. Among such data, bathymetric maps are the most fundamental to all disciplines.

The Seamount Catalog (see http:// earthref.org/SBN) is a hub for a variety of map-related data and user-contributed files.

It functions as an online digital archive for bathymetric maps of seamounts that can be viewed and downloaded in various file formats. Additionally, this catalog contains morphological data characterizing seamounts, sample information, and related grid and multibeam data files, including relevant usercontributed data. Educational materials about seamounts are included in the interlinked collection of Enduring Resources for Earth Science Education (ERESE), including, for example, a lesson plan on hotspot volcanism for high school students (http://earthref.org/ERESE/lessons/hotspots/2006/). All data are stored indefinitely on the professionally managed redundant hard drive arrays of the San Diego Supercomputer Center. All files can be downloaded for free.

Each seamount in the catalog is described in terms of its location, height, volume, elongation, azimuth, irregularity, rifts, morphological classification, and relation to other features. The
GEBCO (General Bathymetric Chart of the Ocean) gazetteer data are included in the database in order to provide information on the history, discovery, and names of the seamounts. Data files for each seamount include a map made from the multibeam data only, a map made from Smith and Sandwell's (1997) predicted bathymetry, a merged map incorporating both data sets, and a map showing the discrepancy between the two data sets. Currently, the Seamount Catalog contains the maps and corresponding raw and processed data from more than 1,800 seamounts covering all of the oceans, with a cumulative data repository exceeding $800 \mathrm{~GB}$.

\section{REFERENCE}

Smith, W.H.F., and D.T. Sandwell. 1997. Global sea floor topography from satellite altimetry and ship depth soundings. Science 277(5334):1,956-1,962.

Anthony A.P. Koppers (akoppers@coas.oregonstate.edu) is Associate Professor, College of Oceanic and Atmospheric Sciences, Oregon State University, Corvallis, OR, USA. Hubert Staudigel is Research Geologist and Lecturer, Institute of Geophysics and Planetary Physics (IGPP), Scripps Institution of Oceanography, University of California, San Diego, La Jolla, CA, USA. Rupert Minnett is a programmer/ analyst, IGPP, Scripps Institution of Oceanography, University of California, San Diego, La Jolla, CA, USA. 